Utah State University

DigitalCommons@USU

Wasatch Dendroclimatology Research

Research Centers

$9-2015$

\title{
Added Value From 576 Years of Tree-ring Records in the Prediction of the Great Salt Lake Level
}

\author{
Robert R. Gillies \\ Utah State University \\ Oi-Yu Chung \\ Utah State University \\ Shih-Yu (Simon) Wang \\ Utah State University \\ R. Justin DeRose \\ U.S. Forest Service \\ Yan Sun \\ Utah State University \\ Follow this and additional works at: https://digitalcommons.usu.edu/wadr \\ Part of the Environmental Sciences Commons
}

\section{Recommended Citation \\ Gillies, Robert R.; Chung, Oi-Yu; Wang, Shih-Yu (Simon); DeRose, R. Justin; and Sun, Yan, "Added Value From 576 Years of Tree-ring Records in the Prediction of the Great Salt Lake Level" (2015). Wasatch Dendroclimatology Research. Paper 9. \\ https://digitalcommons.usu.edu/wadr/9}

This Article is brought to you for free and open access by the Research Centers at DigitalCommons@USU. It has been accepted for inclusion in Wasatch Dendroclimatology Research by an authorized administrator of DigitalCommons@USU. For more information, please contact digitalcommons@usu.edu.

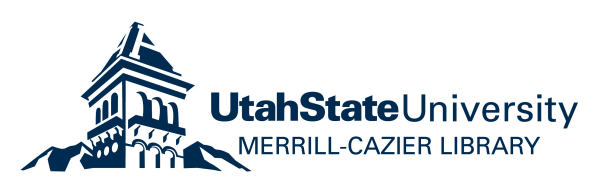




\title{
Added value from 576 years of tree-ring records in the prediction of the Great Salt Lake level
}

\author{
Robert R. Gillies $^{\mathrm{a}, \mathrm{b}, *}$, Oi-Yu Chung ${ }^{\mathrm{a}}$, S.-Y. Simon Wang ${ }^{\mathrm{a}, \mathrm{b}}$, R. Justin DeRose ${ }^{\mathrm{c}}$, Yan Sun ${ }^{\mathrm{d}}$ \\ ${ }^{a}$ Utah Climate Center, Utah State University, Logan, UT, USA \\ ${ }^{\mathrm{b}}$ Department of Plants, Soils, and Climate, Utah State University, Logan, UT, USA \\ ${ }^{c}$ U.S. Forest Service Rocky Mountain Research Station, Ogden, UT, USA \\ ${ }^{\mathrm{d}}$ Department of Mathematics and Statistics, Utah State University, Logan, UT, USA
}

\section{A R T I C L E I N F O}

\section{Article history:}

Received 5 December 2014

Received in revised form 25 May 2015

Accepted 28 August 2015

Available online 4 September 2015

This manuscript was handled by

Konstantine P. Georgakakos, Editor-in-Chief,

with the assistance of Ana P. Barros,

Associate Editor

\section{Keywords:}

Great Salt Lake

Drought

Water

Tree-ring

Forecast

\begin{abstract}
S U M M A R Y
Predicting lake level fluctuations of the Great Salt Lake (GSL) in Utah - the largest terminal salt-water lake in the Western Hemisphere - is critical from many perspectives. The GSL integrates both climate and hydrological variations within the region and is particularly sensitive to low-frequency climate cycles. Since most hydroclimate variable records cover less than a century, forecasting the predominant yet under-represented decadal variability of the GSL level with such relatively short instrumental records poses a challenge. To overcome data limitations, this study assesses two options: (1) developing a model using the observational GSL elevation record of 137 years to predict itself; (2) incorporating the recently reconstructed GSL elevation that utilized 576 years worth of tree-ring records into the predictive model. It was found that the statistical models that combined the tree-ring reconstructed data with the observed data outperformed those that did not, in terms of reducing the root mean squared errors. Such predictive models can serve as a means toward practical water risk management.
\end{abstract}

(c) 2015 Elsevier B.V. All rights reserved.

\section{Introduction}

Located in the semi-arid Intermountain West of the U.S.A, the Great Salt Lake (GSL) integrates the region's hydroclimate over its broad watershed (Fig. 1a). The level of the large shallow lake is controlled by direct influx from precipitation and indirect inflow from major rivers, both of which are offset by evaporation primarily during the summer months. Due to its large surface area that is contained within a closed basin, fluctuations in the GSL level duly reflect the hydroclimate conditions of the region: i.e. the highest water mark lags after the peak in the precipitation regime (of the region's prominent wet-dry cycle) while the lowest water mark occurs after the onset of the low point in the precipitation regime (Wang et al., 2010), a condition oftentimes created by persistent drought. The lake level fluctuation (Fig. 1b) therefore records regional hydroclimate variability, especially at low frequencies (Lall and Mann, 1995; Mann et al., 1995; Wang et al., 2010, 2012). Climate forecasts for both the GSL level and volume have been attempted: For example, atmospheric circulation indices have been explored

\footnotetext{
* Corresponding author at: 4825 Old Main Hill, Logan, UT 84322, USA

E-mail address: Robert.Gillies@usu.edu (R.R. Gillies).
}

as to their role in controlling the GSL level (Moon and Lall, 1996; Gillies et al., 2011; Wang et al., 2012). Additionally, time-series modeling techniques have been developed in order to predict future GSL levels, though most of the models are only applicable over the short-term of 1-2 years (Lall et al., 1996, 2006).

Focusing on the decadal-scale variability of the GSL level, Wang et al. (2010) discovered that the GSL level is highly coherent with, yet opposite to, the tropical central Pacific sea surface temperature (SST) anomalies at the 10-15 year timescale. The coherency occurs through a unique atmospheric teleconnection excited during the transition phases of this 10-15 year oscillation; this affects precipitation within and around the Great Basin through a trans-Pacific atmospheric wave train (Wang et al., 2011). With regard to the connection that was discovered, Gillies et al. (2011) developed a principal component-lagged regression model that was able to predict the GSL level out as far as 8 years (Fig. 1b). It is also noteworthy that Gillies et al.'s GSL forecast, that began in 2008 and lead up to 2015 (delineated and indicated by arrow in Fig. 1b), was validated with in-situ observations (up to 2013) and showed remarkable consistency, most notably in forecasting the upturn that occurred in 2010-2011 and the downturn thereafter at 2012. At the time of the prediction, the 2010-2011 


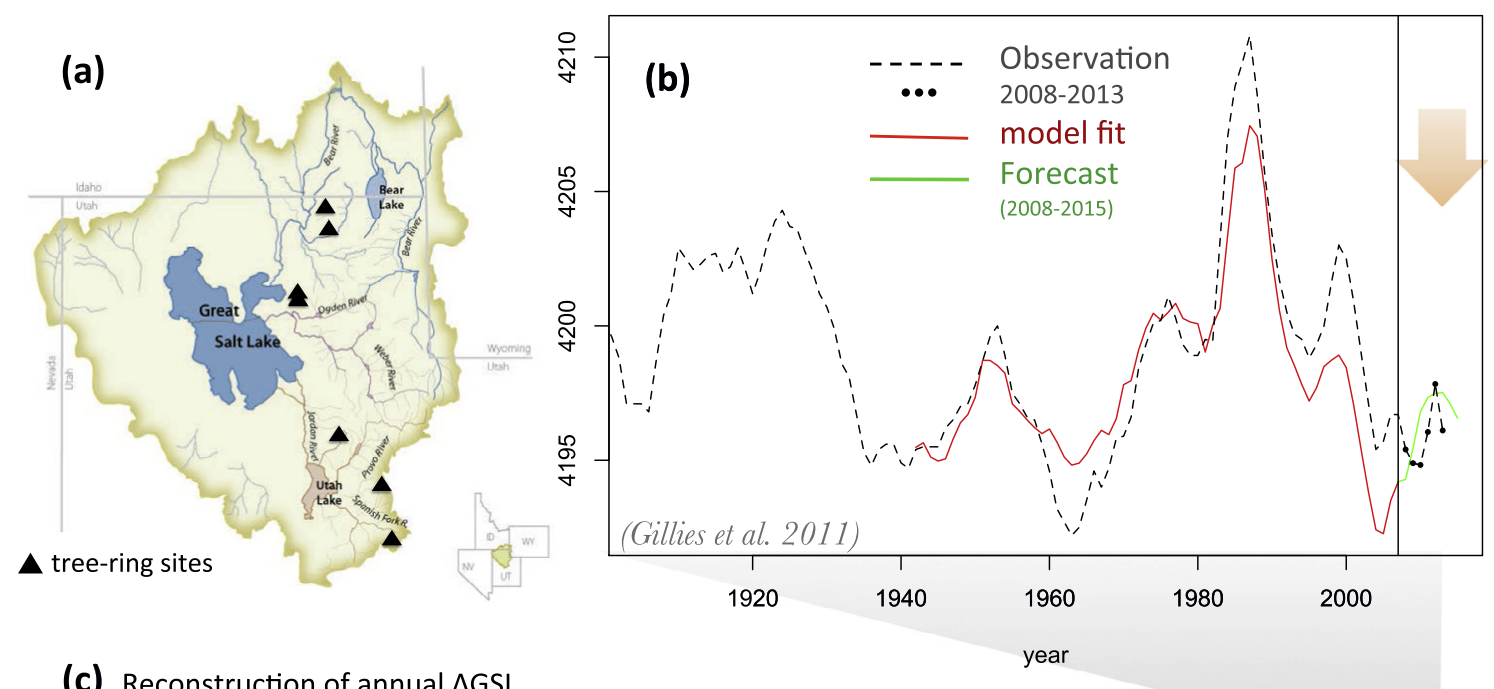

(c) Reconstruction of annual $\triangle \mathrm{GSL}$

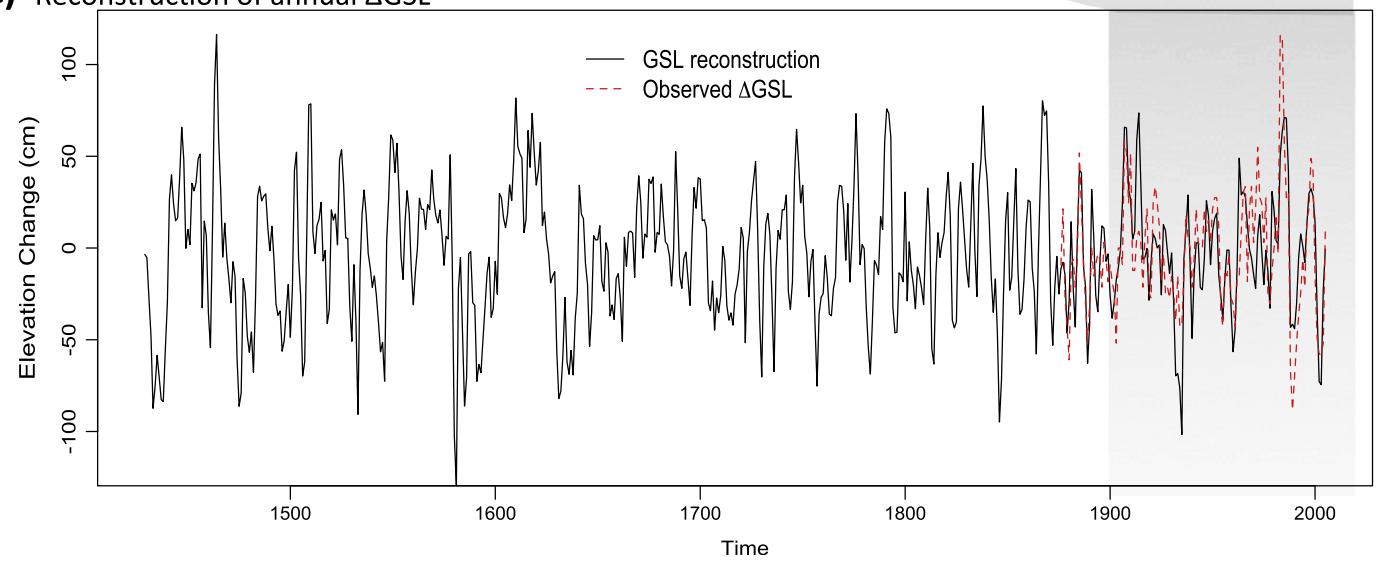

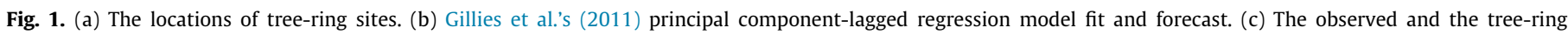
reconstructed annual $\Delta G S L$.

increase in the GSL level had yet to occur; this circumstance supported the connection proposed in Wang et al. (2010), i.e. that the so-called Pacific Quasi-Decadal Oscillation (QDO) figured as a dominant climate phenomenon in the Intermountain West and was a strong contemporary driver of the region's hydroclimate.

However, the GSL level forecast, developed by Gillies et al. (2011), exhibited a wet bias that persisted for two decades followed by a dry bias for roughly a similar time span (Fig. 1b). Such biases of prolonged wet/dry apparently are linked to multi-decadal variability, notably a 30-50 year oscillation (Wang et al., 2012), which also influences the hydroclimate in and around the GSL watershed (Gray et al., 2004). At the time, multi-decadal variability was not incorporated within the GSL model of Gillies et al. (2011); this was due to the insufficient length of the historical observational data ( $\sim 100$ years). Noticing the data gap, DeRose et al. (2014) developed a 576-year (1429-2005) reconstruction of the GSL level tendency (water year minus previous water year; Fig. 1c) utilizing tree-ring width data collected from sites within the GSL watershed (Fig. 1a). Just like the GSL level, annual radial increments (i.e. ring widths) in trees respond to and so, reflect such meteorological variables like effective precipitation, air temperature, and vapor pressure deficit (Cook and Kairiukstis, 1990). In vegetation systems that are strongly limited by the release of winter snowpack (i.e., the Intermountain West), ring-width increment also integrates available moisture from the current and previous water years: In this regard, tree-ring chronologies record low frequency hydroclimatology and so, serve as a good proxy for the GSL level. Moreover, robust statistical tests verified the temporal stability of the GSL model over the instrumental period (1876-2005) confirming that the tree-ring-based reconstruction represented about $60 \%$ of pre-instrumental variability in the GSL level (DeRose et al., 2014).

Given the aforementioned progress in precipitation reconstructions and the inherent limitation in Gillies et al.'s (2011) technique in predicting the GSL level (i.e. not being able to account for multidecadal variability), we hypothesized that a much longer period of record of lake level, i.e. one that captures the multi-decadal variability, should in theory improve the former GSL level prediction. Therefore we examined and compared further, the prediction of the GSL level derived from the observed GSL data alone in conjunction with a considerably longer-term tree ring-reconstruction of the GSL. In doing so, we explored the potential of tree-ring reconstructions of lake level enhancing our prior prediction of hydroclimate variability in a closed-basin lake like that of the GSL.

\section{Model development}

Both the studies of Gillies et al. (2011) and DeRose et al. (2014) focused on the tendency of the GSL level (i.e. the current water year minus the previous one) and used it to reconstruct the actual lake level. Thus, the ensuing analysis focuses on the tendency of the GSL level for both observed and tree-ring reconstructed data, denoted hereafter as $\triangle \mathrm{GSL}$. We first examined a prediction model based solely upon the observed $\Delta \mathrm{GSL}$, i.e. using $\Delta \mathrm{GSL}$ to predict $\Delta G S L$ itself. We then used a model that combined both the observed and the tree-ring reconstructed $\Delta \mathrm{GSL}$ to forecast the same time 
period. To complete the analysis, we compared the models' RMSE using a cross-validation approach - as outlined in Section 3.

\subsection{Observed model: ObsAR}

According to the autocorrelation functions (ACF) and the partial autocorrelation functions (PACF) of the observed $\triangle \mathrm{GSL}$ series, the data series is auto-correlated to lags between 16 and 20 years (Fig. 2); this suggests the appropriate usage of an Autoregressive (AR) model. For simplicity, we call this model ObsAR. Since AR models are assumed to have a mean of zero, we centered the data series (i.e. removing the series mean) before fitting it into a model. Using data up to the year 2000, we applied the commonly used principle of Minimum Description Length (MDL) (Rissanen, 1978, 1983) and Akaike Information Criterion (AIC) (Akaike, 1969, 1979) to determine the model size. The final model of choice was defined as:

$$
\begin{aligned}
\Delta \mathrm{GSL}(t)= & 0.61 \Delta \mathrm{GSL}(t-1)-0.05 \Delta \mathrm{GSL}(t-2)+0.16 \Delta \mathrm{GSL}(t-3) \\
& -0.11 \Delta \mathrm{GSL}(t-4)-0.23 \Delta \mathrm{GSL}(t-5) \\
& -0.03 \Delta \mathrm{GSL}(t-6)+0.1 \Delta \mathrm{GSL}(t-7) \\
& +0.011 \Delta \mathrm{GSL}(t-8)-0.04 \Delta \mathrm{GSL}(t-9) \\
& -0.06 \Delta \mathrm{GSL}(t-10)+0.025 \Delta \mathrm{GSL}(t-11) \\
& -0.07 \Delta \mathrm{GSL}(t-12)+0.13 \Delta \mathrm{GSL}(t-13) \\
& -0.01 \Delta \mathrm{GSL}(t-14)+0.12 \Delta \mathrm{GSL}(t-15) \\
& -0.1 \Delta \mathrm{GSL}(t-16)-0.23 \Delta \mathrm{GSL}(t-17)+Z(t) .
\end{aligned}
$$

Here, $\Delta \mathrm{GSL}(t)$ denotes the GSL tendency at time $(t)$ while $(t-n)$ denotes the period for the $n$th previous year. $Z(t)$ represents a white noise process at time $(t)$ with a zero mean and time-invariant finite variance. In order to incorporate the decadal-scale variability identified by earlier research (Lall and Mann, 1995; Wang et al., 2012) this model was regressed upon The actual and model fitted $\triangle \mathrm{GSL}$ are displayed in Fig. 2c. The RMSE between the observed and the model fitted value was determined as $22.54 \mathrm{~cm} \mathrm{yr}^{-1}$. In comparison with the standard deviation of the annual $\Delta G S L$ of $32.76 \mathrm{~cm} \mathrm{yr}^{-1}$, this level of RMSE seems acceptable. Additionally, Fig. 4a shows the ACF and PACF of the model residuals which fell within the $95 \%$ confidence interval indicating that the residuals are serially uncorrelated at the 95\% confidence level; this suggested that the model was reasonable in terms of capturing the dynamic structure of the data. Using this at least the previous 17 years in order to predict the present year.

model to predict five years ahead (i.e. 2001-2005), the RMSE between the observed and forecasted $\triangle G S L$ was computed as $17.68 \mathrm{~cm} \mathrm{yr}^{-1}$.

\subsection{Tree-ring model 1: TreeARX-1}

Next we examined the influence of adding the tree-ring reconstructed $\triangle G S L$ into the model. The tree-ring $\triangle \mathrm{GSL}$ series was treated as an exogenous variable and an ARX (Autoregressive with Exogenous) model was implemented - we refer to this model as TreeARX-1. The cross-correlation function between the observed and tree-ring reconstructed $\triangle G S L$ series revealed significant correlations up to $\sim 20$ lags (not shown). As before, in consideration of the principle of MDL, the ARX model of choice was:

$$
\begin{aligned}
\Delta \mathrm{GSL}(t)= & 0.61 \Delta \mathrm{GSL}(t-1)-0.04 \Delta \mathrm{GSL}(t-2)+0.16 \Delta \mathrm{GSL}(t-3) \\
& -0.12 \Delta \mathrm{GSL}(t-4)-0.22 \Delta \mathrm{GSL}(t-5) \\
& -0.02 \Delta \mathrm{GSL}(t-6)+0.08 \Delta \mathrm{GSL}(t-7) \\
& +0.013 \Delta \mathrm{GSL}(t-8)-0.05 \Delta \mathrm{GSL}(t-9) \\
& -0.06 \Delta \mathrm{GSL}(t-10)+0.051 \Delta \mathrm{GSL}(t-11) \\
& -0.09 \Delta \mathrm{GSL}(t-12)+0.14 \Delta \mathrm{GSL}(t-13) \\
& -0.01 \Delta \mathrm{GSL}(t-14)+0.13 \Delta \mathrm{GSL}(t-15) \\
& -0.12 \Delta \mathrm{GSL}(t-16)-0.27 \Delta \mathrm{GSL}(t-17) \\
& +0.06 \mathrm{TR}(t-18)+0.02 \mathrm{TR}(t-19) \\
& +0.08 \mathrm{TR}(t-20)-0.09 \mathrm{TR}(t-21)+Z(t) .
\end{aligned}
$$

For the auto-regressive part, $\Delta \mathrm{GSL}(t)$ again denotes the GSL tendency at time $(t)$ while $(t-n)$ denotes the period for the previous $n$th year. For the exogenous factor, $\operatorname{TR}(t-n)$ here denotes the treering data series at time $(t-n) . \mathrm{Z}(t)$ represents a white noise process at time $(t)$ with a zero mean and finite constant variance; this model also makes use of the previous 17 years of observed $\Delta \mathrm{GSL}$ while taking 4 orders of the tree-ring data that were delayed for 18 years (i.e. using four consecutive years of data that were delayed for 18 years). The observed and model fitted $\Delta$ GSL are displayed in Fig. 3a. The RMSE between the observed and the fitted values is $22.33 \mathrm{~cm} \mathrm{yr}^{-1}$, which is close to that of ObsAR. The ACF and PACF plot in Fig. $4 \mathrm{~b}$ shows that the model residuals are serially uncorrelated at the $95 \%$ confidence interval, indicating that the model was able to capture the data structure. Using this model to forecast for the period of 2001-2005, the RMSE result was $9.802 \mathrm{~cm}$, about $8 \mathrm{~cm}$ less than that of ObsAR, which indicates prediction improvement.

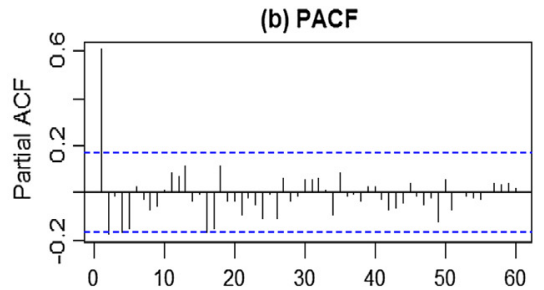

(c) ObsAR model fit and forecast

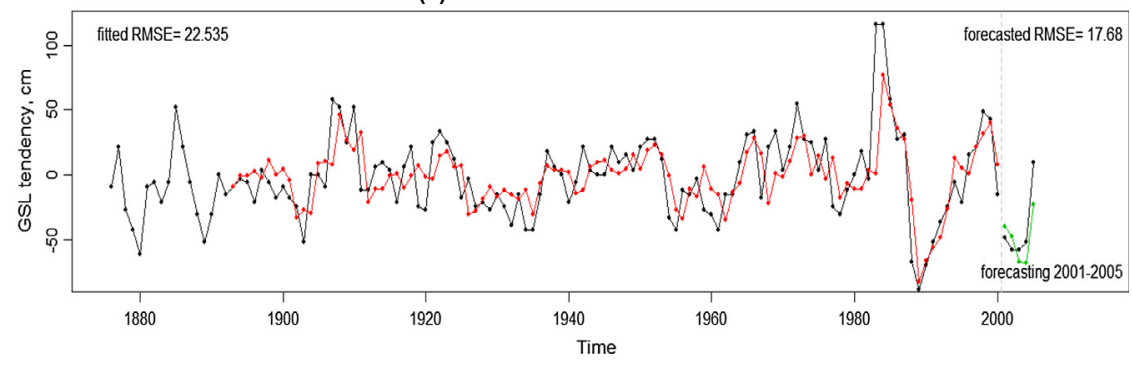

Fig. 2. The ACF (a) and PACF (b) of observed $\triangle G S L$, and (c) the fitted (red) and forecasted (green) $\triangle G S L$ of model ObsAR. (For interpretation of the references to color in this figure legend, the reader is referred to the web version of this article.) 
(a) model TreeARX-1

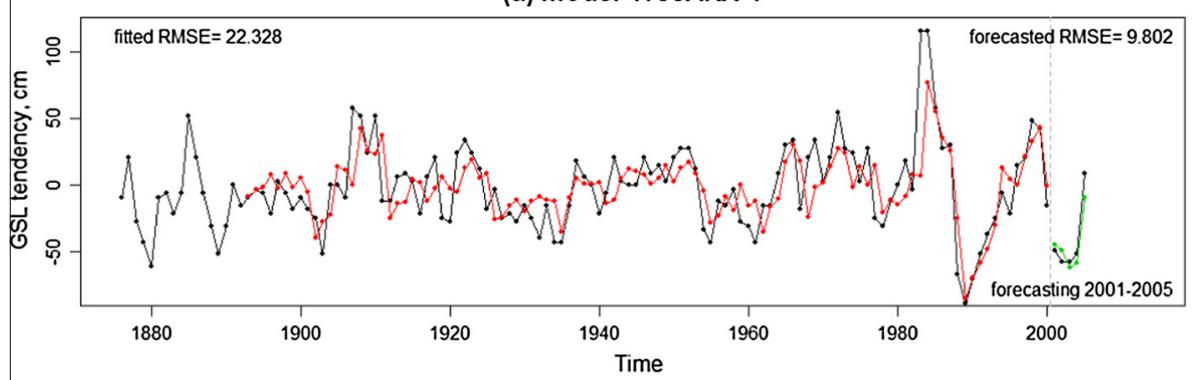

(b) model TreeARX-2

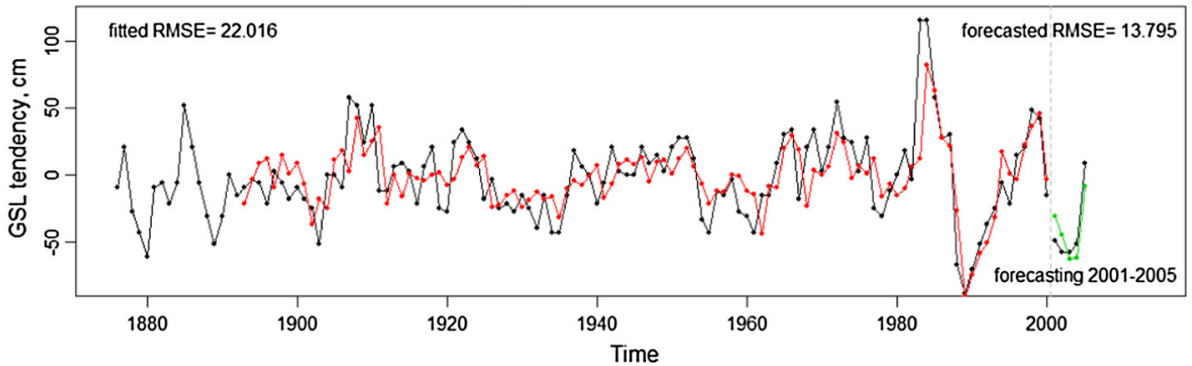

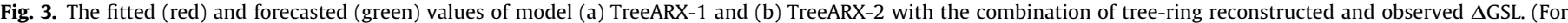
interpretation of the references to color in this figure legend, the reader is referred to the web version of this article.)
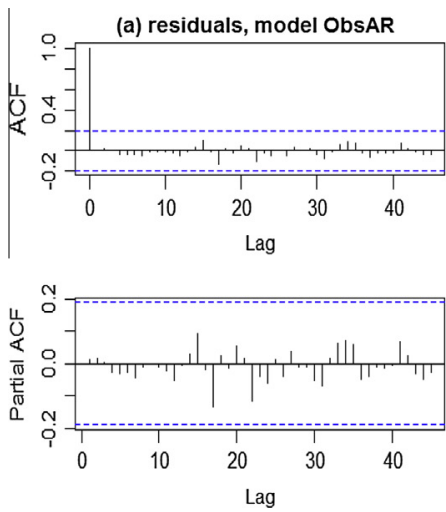

(b) residuals, model TreeARX-1
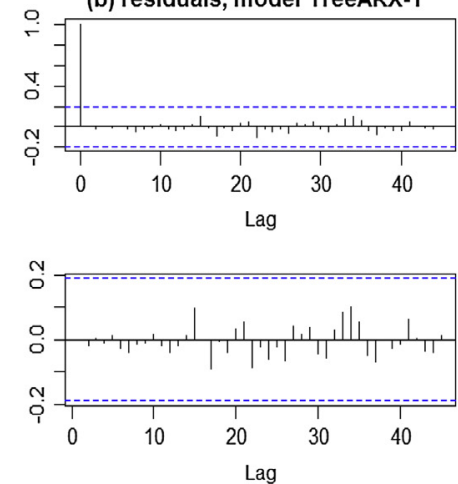

(c) residuals, model TreeARX-2
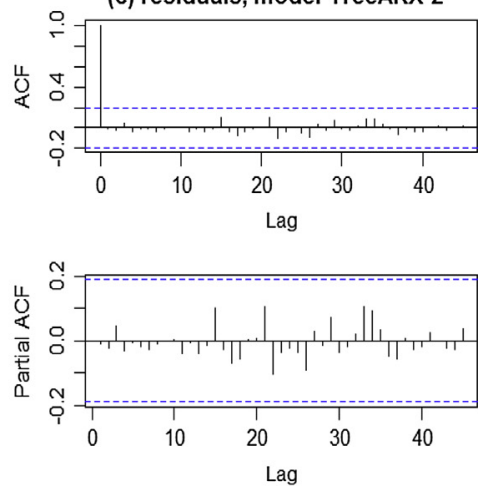

Fig. 4. The ACF and PACF of the residuals from model (a) ObsAR, (b) TreeARX-1, and (c) TreeARX-2.

\subsection{Tree-ring model 2: TreeARX-2}

A further refinement was to use AIC to select the model order instead of using MDL (as was the case in the previous model), whereupon a somewhat different ARX model was generated (denoted as TreeARX-2):

$$
\begin{aligned}
\Delta \mathrm{GSL}(t)= & 0.62 \Delta \mathrm{GSL}(t-1)-0.06 \Delta \mathrm{GSL}(t-2)+0.17 \Delta \mathrm{GSL}(t-3) \\
& -0.11 \Delta \mathrm{GSL}(t-4)-0.21 \Delta \mathrm{GSL}(t-5) \\
& -0.06 \Delta \mathrm{GSL}(t-6)+0.09 \Delta \mathrm{GSL}(t-7) \\
& +0.02 \Delta \mathrm{GSL}(t-8)-0.06 \Delta \mathrm{GSL}(t-9) \\
& -0.04 \Delta \mathrm{GSL}(t-10)+0.01 \Delta \mathrm{GSL}(t-11) \\
& -0.12 \Delta \mathrm{GSL}(t-12)+0.18 \Delta \mathrm{GSL}(t-13) \\
& -0.01 \Delta \mathrm{GSL}(t-14)+0.13 \Delta \mathrm{GSL}(t-15) \\
& -0.13 \Delta \mathrm{GSL}(t-16)-0.27 \Delta \mathrm{GSL}(t-17) \\
& +0.08 \mathrm{TR}(t-18)-0.003 \mathrm{TR}(t-19) \\
& +0.12 \mathrm{TR}(t-20)-0.19 \operatorname{TR}(t-21) \\
& +0.20 \mathrm{TR}(t-22)-0.23 \operatorname{TR}(t-23)+Z(t)
\end{aligned}
$$

Similarly, this model applies the previous 17 years of observed $\Delta \mathrm{GSL}$, but in this instance takes 6 orders of the tree-ring data delayed for 18 years. The observed and the fitted response values are displayed in Fig. 3b. The RMSE was computed as $22.02 \mathrm{~cm} \mathrm{yr}^{-1}$. For forecasting $\Delta G S L$ for the period 2001-2005, the RMSE was found to be $13.8 \mathrm{~cm} \mathrm{yr}^{-1}$, which is $3.9 \mathrm{~cm}$ less than that of ObsAR. Likewise as before, the model residuals were serially uncorrelated at the $95 \%$ confidence interval (Fig. 4c) indicating that this model also captured the data structure well.

It is known that tree rings do not reflect extreme wet periods as precisely as they do for drought periods; this is due to the fact that when field capacity (soil saturation) is reached (particularly so in very wet years), additional precipitation runs-off and is not recorded in tree-ring growth: Such a "wet" bias is still visible in Fig. 3, a discussion of which can be found in DeRose et al. (2014).

\section{Prediction evaluation}

The prediction performance of all three models (ObsAR, TreeARX-1, and TreeARX-2) was evaluated over the 2001-2005 
period. In essence, both TreeARX models exhibited improvement when compared with that of the ObsAR model based solely upon their RMSEs. Since the $\triangle G S L$ during this period of time was in a downward trend turning upward, we investigated further the $\Delta$ GSL model performance under differing circumstances of flux: Therefore, we tested three forecasting situations when the $\Delta G S L$ was in: (1) a downtrend (1985-1989); (2) an uptrend (1989-1993); and (3) an upward trend turning downward (1996-2000). All model coefficients were held constant; however the observed data used was up to the year before the forecasting period began. For example, as is shown in the first row of Fig. 5, when data up to 1984 were used for the purpose of prediction, we forecasted five years ahead for 1985-1989. In this period, the results indicate that the TreeARX-2 model produced the smallest RMSE $\left(19.6 \mathrm{~cm} \mathrm{yr}^{-1}\right)$. For the forecasting period of 1989-1993, the ObsAR model performed the best with an RMSE of $7.8 \mathrm{~cm} \mathrm{yr}^{-1}$, or 1.6 and $6.1 \mathrm{~cm} \mathrm{yr}^{-1}$ less than TreeARX-1 and TreeARX-2 models, respectively. For the forecasting period of 1996-2000, both TreeARX models performed well and their RMSEs were approximately $13.5 \mathrm{~cm} \mathrm{yr}^{-1}$, which are about $3 \mathrm{~cm} \mathrm{yr}^{-1}$ less than that of ObsAR. Summarizing, when the $\triangle \mathrm{GSL}$ was in a downtrend (first row Fig. 5) or in an upward turning down (third row Fig. 5), the RMSEs of TreeARX-2 were the smallest; but when the $\Delta G S L$ was up-trending, the ObsAR model resulted in the smallest RMSE.

The ultimate goal in examining and developing different model configurations was to reduce model error with a forecast in mind. Thus, we attempted longer predictions (up to 2013) using the same model coefficients. A total of eight cross-validations were conducted. For the first set, we fitted the observed data up to 2001 into the models and used them to predict for 2002-2006. For the second set we fitted the data up to 2002 and predicted for 2003-2007, and so on. For the last set we fitted the data up to 2008 and predicted for 2009-2013. We then calculated the RMSEs for each set and each model. As is shown in Fig. 6, all three models' RMSEs increased
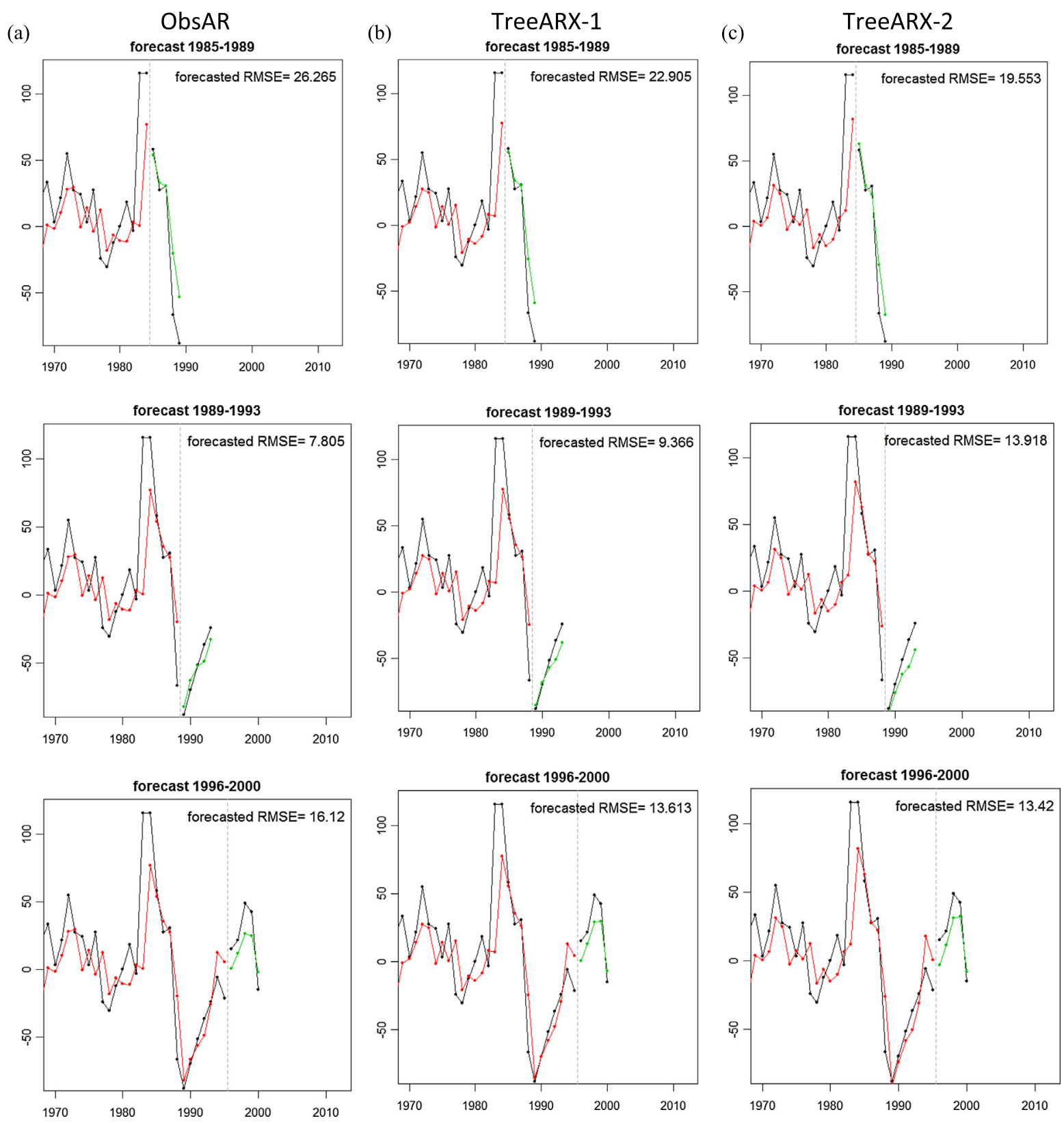

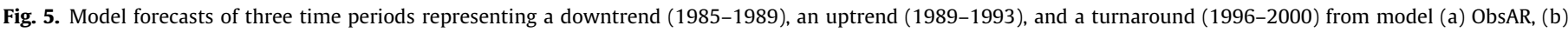
TreeARX-1, and (c) TreeARX-2. 


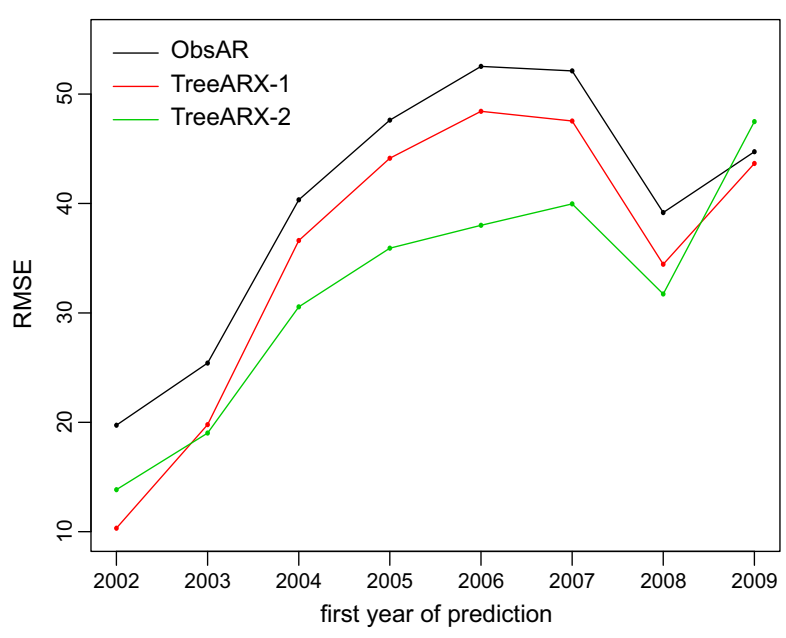

Fig. 6. The cross-validating RMSEs of the $\Delta \mathrm{GSL}$ forecast from the three models,

as time passed. Of special note, the two TreeARX models performed consistently better than the ObsAR model, except for year 2009. In some sets, the RMSE of ObsAR doubled compared to those of TreeARXs. To summarize our findings, the average performance in terms of the RMSEs was $40.2 \mathrm{~cm} \mathrm{yr}^{-1}$ with model ObsAR, $35.61 \mathrm{~cm} \mathrm{yr}^{-1}$ with TreeARX-1, and $32.06 \mathrm{~cm} \mathrm{yr}^{-1}$ with TreeARX-2. It is noteworthy that the average RMSE of TreeARX-2 was still less than the standard deviation of annual $\Delta G S L$ (i.e. $32.76 \mathrm{~cm} \mathrm{yr}^{-1}$ ).

For the purposes of forecasting the near future (2014-2018), we used the observed data up to 2013 to estimate the model coefficients for ObsAR, and used all tree-ring reconstruction data to estimate the ARX model coefficients. The results indicate that all three models produced similar magnitudes in terms of RMSE between the observed and the predicted model values; the difference between each other is less than $1 \mathrm{~cm} \mathrm{yr}^{-1}$ (not shown). Of importance was the fact that, even though the TreeARX models were predicting at least nine years ahead of the data available, the forecasted 2014-2018 $\Delta$ GSL turned out to be quite similar among all models. All models expect a continual decline in the GSL levels that should bottom out in 2017 prior to rising again (Fig. 7). The fact that the three predictions look similar also illustrates that,

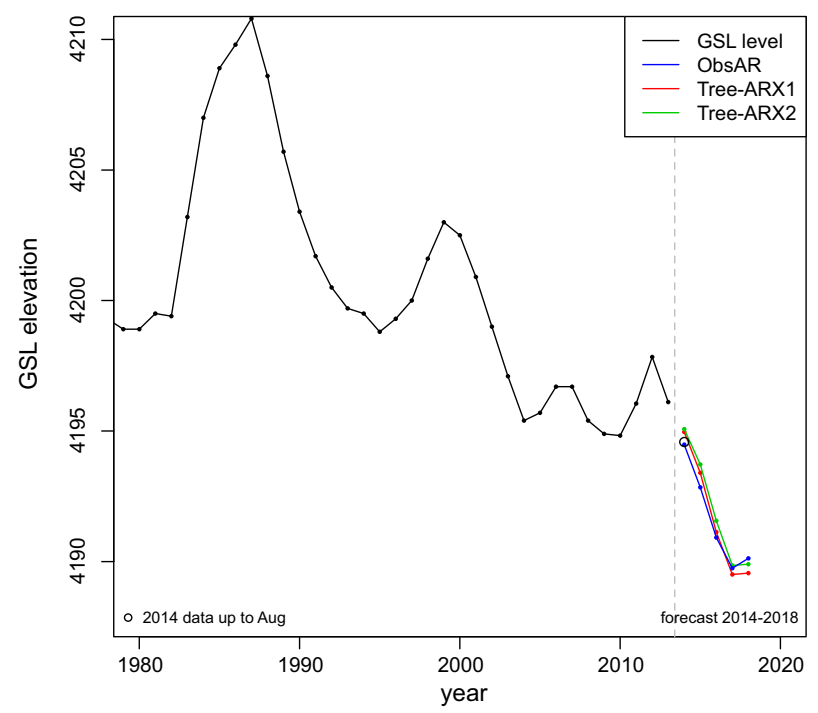

Fig. 7. Projection of the GSL elevation integrated from the model-predicted $\Delta \mathrm{GSL}$ for the next 5 years from 2014 to 2018 . Note that the black circle in 2014 is the observation value for eleven months, October 13-August 14. even though the TreeARX models only used in-situ data up to 2005, their prediction power is comparable to that of ObsAR that used up-to-date data.

\section{Discussion and conclusion}

We compared three time-series models for the prediction of the $\triangle G S L$ and the GSL level, and evaluated their performance. The first model used the past $\Delta$ GSL data to predict itself (autoregressive). The second and the third were ARX models that incorporated the tree-ring reconstructed time-series as exogenous regressors. The complexity of the ARX models was determined via the commonly used methods of AIC and MDL. Results showed that all three models performed quite similarly in predicting $\triangle \mathrm{GSL}$. However, the incorporation of tree-ring data resulted in a noticeable reduction in the RMSEs for both the model fitted and the forecasted values (i.e. obtaining better skill); this shows proof of concept, i.e. that the much longer record of tree-ring-reconstructed $\Delta \mathrm{GSL}$, which is more complete representation of multi-decadal variability for the region, can be applied as an effective prediction tool. Also implied is the possibility of a similar combination whereby gauged stream flow data and reconstructed flow should, at least in theory, improve hydrological forecasting for the streams and the rivers in the region as well.

Nevertheless, further improvement of the forecast models while enhanced is still imperfect; this is simply because tree-ring reconstructions do not capture all the variability associated with the $\Delta \mathrm{GSL}$ (see DeRose et al., 2014), despite the fact that they do supply additional information on the lower-frequency variations. However, the putative bias of tree rings in depicting wet extremes, while still a limiting factor, does not appear overly restrictive. Greater uncertainty perhaps lies in human interference that adjusts the GSL level such as diversions and water consumption (which are difficult, if not impossible, to reconcile); these were not directly accounted for in the GSL level data (i.e. water that is used by people never shows up in the lake). Regardless, reconstructed time-series that extend back many centuries did result in an increase in the amount of information that can be statistically decomposed. Therefore, by incorporating both historical and reconstructed records of climate variability into a time series model, it is possible to not only assemble, but also enhance model predictive power.

It seems likely that the physiology associated with water uptake by the trees (i.e. when the soil reaches field capacity) is a constraint that will result in an under-prediction of the lake level during wet periods - becoming more so under particularly wet conditions (DeRose et al., 2014; or Fig. 1c). However, ones' reliance on a forecast during periods of prolonged precipitation events, such as those that resulted in the rare 1983 flood alongside subsequent wet years (i.e. 1984-1987) that ultimately led to pumping water out of the lake in 1987 (Morrisette, 1988), should be tempered during such precipitation anomalies. Alternatively, tree-ring records from the region track dry periods exceptionally well (see DeRose et al., 2014) such that forecasts of low GSL levels should be taken as bona fide periods of drought. While not capturing the magnitude of the lake level peak elevation entirely, results from this study indicate that the forecasts using dendrochronology still result in an improvement in model skill for multi-year prediction.

Water management in the semi-arid GSL region (i.e., Wasatch Front), which hosts a burgeoning population of over 2 million people, requires forecasting tools to aid decision-making regarding storage, delivery, and conservation. The tree-ring-based GSL model developed here provides the most accurate forecasting tool to-date for the region. Furthermore, a comparison of stream flow variability for three GSL tributaries, the Bear River (DeRose et al., 2014), 
the Logan River (Allen et al., 2013), and the Weber River (Bekker et al., 2014) showed strong low frequency coherency between these rivers over the past four centuries. If regional stream flow is coherent, and GSL level is primarily sensitive to inflow variations (Mohammed and Tarboton, 2012), then a GSL forecast is an informal indicator of the dominant hydroclimate driver (i.e., the QDO) governing precipitation delivery to the region. Moreover, creditable and more reliable forecasts go a long way toward assisting water managers characterize the state of current climate (e.g., wet or dry) and institute the use of climate-based predictive tools as a guide toward proactive water management practices.

\section{Acknowledgments}

Support coming from grants WaterSMART R13AC80039, NNX13AC37G, and the Utah State University Agricultural Experiment Station is appreciated.

\section{References}

Akaike, H., 1969. Fitting autoregressive models for prediction. Ann. Inst. Stat. Math. 21, 243-247.

Akaike, H., 1979. A Bayesian extension of the minimum AIC procedure of autoregressive model fitting. Biometrika 66, 237-242.

Allen, E.B., Rittenour, T.M., DeRose, R.J., Bekker, M.F., Kjelgren, R., Buckley, B.M., 2013. A tree-ring based reconstruction of Logan River streamflow, northern Utah. Water Resour. Res, 49, 8579-8588.

Bekker, M.F., Justin DeRose, R., Buckley, B.M., Kjelgren, R.K., Gill, N.S., 2014. A 576year Weber River streamflow reconstruction from tree rings for water resource risk assessment in the Wasatch Front, Utah. JAWRA J. Am. Water Resour. Assoc. 50, 1338-1348.
Cook, E.R., Kairiukstis, L.A., 1990. Methods of Dendrochronology: Applications in the Environmental Sciences. Springer.

DeRose, R.J., Wang, S.-Y., Buckley, B.M., Bekker, M.F., 2014. Tree-ring reconstruction of the level of Great Salt Lake, USA. The Holocene 24, 805-813.

Gillies, R.R., Chung O.-Y. Wang S.-Y., Kokoszka, P., 2011. Incorporation of Pacific SSTs in a time series model towards a longer-term forecast for the Great Salt Lake elevation. J. Hydrometeor. 12, 474-480.

Gray, S.T., Jackson, S.T., Betancourt, J.L., 2004. Tree-ring based reconstructions of interannual to decadal-scale precipitation variability for northeastern Utah. J. Am. Water Resour. Assoc. 40, 947-960.

Lall, U., Mann, M.E., 1995. The Great Salt Lake: a barometer of low-frequency climatic variability. Water Resour. Res. 31, 2503-2515.

Lall, U., Sangoyomi, T., Abarbanel, H., 1996. Nonlinear dynamics of the Great Salt Lake: nonparametric short-term forecasting. Water Resour. Res. 32, 975-985.

Lall, U., Moon, Y.-I., Kwon, H.-H., Bosworth, K., 2006. Locally weighted polynomia regression: parameter choice and application to forecasts of the Great Salt Lake. Water Resour. Res. 42, 1-11.

Mann, M., Lall, U., Saltzman, B., 1995. Decadal-to-centennial-scale climate variability: insights into the rise and fall of the Great Salt Lake. Geophys. Res. Lett. 22, 937-940.

Moon, Y.-I., Lall, U., 1996. Atmospheric flow indices and interannual Great Salt Lake variability. J. Hydrol. Eng. 1, 55-62.

Morrisette, P.M., 1988. The rising level of the Great Salt Lake: impacts and adjustments. Bull. Am. Meteorol. Soc. 69, 1034-1040.

Rissanen, J., 1978. Modeling by shortest data description. Automatica 14, 465-471.

Rissanen, J., 1983. A universal prior for integers and estimation by minimum description length. Ann. Stat., 416-431

Mohammed, I.N., Tarboton, D.G., 2012. An examination of the sensitivity of the Great Salt Lake to changes in inputs. Water Resour. Res. 48, W11511.

Wang, S.-Y., Gillies, R.R., Reichler, T., 2012. Multi-decadal drought cycles in the Great Basin recorded by the Great Salt Lake: modulation from a transitionphase teleconnection. J. Climate 25, 1711-1721.

Wang S.-Y, Gillies, R.R. Jin, J., Hipps, L.E, 2010. Coherence between the Great Salt Lake level and the Pacific quasi-decadal oscillation. J. Climate 23, 2161-2177.

Wang, S.-Y., Gillies, R.R., Hipps, L.E., Jin, J., 2011. A transition-phase teleconnection of the Pacific quasi-decadal oscillation. Climate Dynam. 36, 681-693. 